\title{
An Overview of Anthropological Regional Studies
}

\author{
Daming Zhou $\cdot$ Xuzhi Zhan $\cdot$ Yu Cao $\cdot$ Liang Chen
}

Received: 2 January 2019 /Accepted: 25 February 2019 / Published online: 03 April 2019 (C) The Author(s). 2019 Open Access This article is distributed under the terms of the Creative Commons Attribution 4.0 International License (http://creativecommons.org/licenses/by/4.0/), which permits unrestricted use, distribution, and reproduction in any medium, provided you give appropriate credit to the original author(s) and the source, provide a link to the Creative Commons license, and indicate if changes were made.

\begin{abstract}
Regional studies in anthropology are vital to the development of the discipline, for they supply anthropology with an approach that moves from individual cases to a holistic understanding of a region. Western anthropologists' interests in researching non-western regions started as early as the Age of Discovery, and regional studies in anthropology, in the United States in particular, are well-organized and systematic. In China, regional studies serve to transcend China's traditional village studies to understand Chinese civilization as a whole. Following this approach, several paradigms, including Skinner's model, were proposed and regional studies were part of Fei Xiaotong's entire academic life. Globalization poses both challenges and opportunities to regional studies while bringing new visions to its practice in China.
\end{abstract}

\section{Zhou}

Migration and Ethnic Studies, Sun Yat-sen University, Blk. 410, No.135 Xingang Xi Road, Guangzhou 510275, China

e-mail: hsszdm@mail.sysu.edu.cn

\section{Zhan · Y. Cao $(\bowtie) \cdot$ L. Chen}

Center for Migration and Ethnic Studies, Sun Yat-sen University, Blk. 410, No.135 Xingang Xi Road, Guangzhou 510275, China

e-mail: zhanxuzhi1989@126.com

Y. Cao

e-mail: rainingkoo@gmail.com

L. Chen

e-mail: oldlamp@qq.com 
Keywords Regional studies · Area studies · Ethnography · Anthropology

\section{Introduction: Anthropology and regional studies}

Although China's anthropological discipline has had many debates on ethnography, little attention has been paid to regional studies, which is closely related to ethnography ${ }^{1}$. In the author's opinion, ethnography is an indispensable and vital tool for anthropological research, while regional studies are the refinement of ethnographies or transcendental forms of the latter. This paper will examine and review both the western and domestic regional studies of anthropology and reflect on their existing problems. It will also explore the trend of development of regional studies and look forward to new orientations and the future of China's anthropological regional studies.

Regional studies as a branch of social sciences are multidisciplinary, collaborative fields of study which are grounded on the assumption that the culture, history, language and other aspects are consistent in a given geographical region. "It brings the scholars of certain areas (including social sciences, humanities, and some natural sciences) together on the basis of their common interest, and by so doing, the disciplinary boundaries are crossed and a multidisciplinary sphere is established. Social scientists who study the universal rules, Orientalists, anthropologists who investigate the differences among cultures, ethnologists, geographers, epidemiologists, geologists and art historians are all involved in this sphere." (Zhou, 2012) Regional studies as a sub-discipline emerged in the United States after the Second World War, supplying the United States' global strategic deployment with a large amount of information on different regions of the world. However, under the anthropological perspective, comprehensive regional studies on the culture of a given area had long existed as a disciplinary tradition, as was substantiated enormously through ethnographic writings.

"Cross-cultural comparison," one of the primary research approaches of anthropology, advocates the in-depth study of human cultures and behaviors from a cross-cultural, holistic perspective (Zhuang, 2003). Therefore, regional studies, with its emphasis on a holistic understanding of a region and more importantly the comparison between regional cultures, have long been a crucial research domain in anthropology. Scholars often refer to areas such as Africa, Oceania, South America, Southeast Asia, East Asia, China, Japan, etc. China's anthropology has, since its commencement, also focused on regions such as the "Tibetan-Yi corridor," "Southwest China minorities region," "rural North China," "the Pearl River Delta area studies" and so forth. The recent "South China studies" and the "pan-South China Sea studies" brought by the inter-disciplinary study of historical anthropology are the new manifestation of the tradition of regional studies in anthropology.

\footnotetext{
${ }^{1}$ Author In the 2014 doctoral entrance examination of the anthropology department in Sun Yat-sen University, two questions were given to the candidates. The first one was on island ethnography which seldom students were able to answer, the second one was on regional studies which few students were able to answer. The test attests to the fact that anthropological training institutions pay little attention to regional studies nowadays.
} 
Concerning the history of anthropology, the origin and rise of anthropology are closely related to regional studies. Anthropology, as a modern discipline, has studied the histories and realities of non-Western people since the sixteenth century, when Europeans met people from the rest of the world. The practice draws on data exclusively from non-Western peoples, literatures and lifestyles (Wang, 2011). The field work and ethnographic writings in such disciplines as African studies, Native American studies and Oceania indigenous peoples studies therefore referred to regions that were non-Western and of the "other." These regional studies prompted the systematic research of marriage and family, kinship systems, social organizations, religions, etc. A massive volume of ethnographies was written based on regional studies, constituting the foundation of the understanding of culture, and the comparison between cultures. Although anthropology has gone through a series of turns and an expansion of research domains, regional studies and the cultural comparative perspective remain important research methods for anthropology.

Theoretically, regional studies combined the concepts of "region" and "culture," allowing generations of anthropologists to develop theories such as that of cultural sphere by cultural assimilationists, cultural area theory from the United States, historical ethnological area theory from the Soviet Union and culture change/acculturation theories. Methodologically, field study, cultural comparisons, the holistic perspective, as well as panoramic ethnography writing are the pillars of regional studies. While anthropology is known for case studies, regional studies are complementary in that they bridge particular, individual cases to the whole, not through inferring from one case to the whole but through compiling cases within a given region and making comparisons among them so as to achieve a panoramic view of the regional culture.

Aside from an education in theory and methodology, regional studies training is necessary for anthropologists. Anthropology traditionally stresses studying regional ethnography as a pedagogical tool. Each student must become familiar with the ethos and the cultures in the designated research region before carrying out fieldwork. Therefore, every anthropological department should set up curricula of regional studies that include such topics as introduction to regional ethnography reading, regional research methods, and modules regarding regional cultures of given regions ${ }^{2}$. Meanwhile, the establishment of regional studies associations and the cataloguing of books according to regions are both relevant measures to carry forward regional studies. Although globalization is sweeping the world, it does not stop scholars from investing efforts on regional studies. Many facets of regional studies have been promoted and developed, such as "Taiwan studies," "Southwest China minorities studies," and "ring of South China Sea studies." In 2009, the themes of regional studies and development were highlighted and discussed among East Asian anthropologists during the first East Asian anthropologists' symposium held at Yunnan University (Xin, 2010). In 2012, at the annual conference of the Taiwan Society for Anthropology and Ethnology, participants reviewed the situation of regional studies. Many scholars agreed that regional studies could test

\footnotetext{
${ }^{2}$ Domestic anthropologists have neglected regional studies, this situation should be altered.
} 
hypotheses of cultural, social, economic or political phenomena, and promote related research topics and theoretical concerns. In the meantime, given that the acceleration of "waves" of migration and globalization have normalized cross-border activities and transformed relationships based on geographical closeness, the question of how anthropology might reflect on regional studies and how it might be revived with new perspectives, theories and methods became the focus of academics.

\section{Discussion: The development of regional studies}

Regions of the other: Western anthropology's traditions of regional studies

As a "Western" discipline, both the rise and development of anthropology were related to Western colonial history. In the nineteenth century, anthropology, a subject of the social sciences found in European and North American countries, was not interested in Western society but in non-Western areas and societies - the early research and classic ethnographies of which laid the foundation of anthropology and enriched the literature of regional studies. In this regard, regional studies within Western anthropology involved research of "the Other." Later on, area studies that derived from and thrived in the United States developed a systematic and nuanced understanding of regional studies and generated numerous research works, supplying much to regional studies with unique theories and methodologies. After the Second World War, the crisis that struck anthropology also affected regional studies, causing Western anthropological academics to reflect on their traditions and seek new directions for regional studies.

\section{An early stage of "non-Western" regional studies}

Early anthropological studies examined the histories and realities of the "non-Western" ethnic groups associated with Europe. There were two kinds of these non-Western ethnic groups, one being the tribal ethnos with small populations, unsophisticated religions and low productivity; the other being civilized nations that later became colonies or semi-colonies of Western countries. The two types of non-Western ethnos corresponded to two clear-cut regions, with the former denoting Africa and Oceania while the latter denoting the Middle East, Southeast Asia, Latin America and other places. On the one hand, Western countries regarded tribal ethnic groups as their past; it was considered that the study of the latter would lead to a better understanding of Europeans' own cultures. On the other hand, since Western countries had established colonial rule over some tribal ethnic groups, the accumulated knowledge of the cultures of these colonies helped consolidate Europeans' reign. At that time, a large number of professionally trained anthropologists and colonial officials with anthropological knowledge were deployed to these regions, and abundant funds and their academic interests allowed them to conduct long time field-study on the cultures, societies, and economies of these regions, producing numerous ethnographic works. These research works are very substantial and have distinct regional studies flavor, forming the tradition of anthropological regional studies. Since then, panoramic ethnographic writing has 
contributed to regional studies, out of which some of the most fundamental and classical theories of anthropology emerged.

One of the critical domains of early "non-Western" regional studies was African Studies. The United Kingdom and France set up African research institutions, such as the Committee of Historical and Scientific Studies of French West Africa founded in by François Joseph Clozel, Governor-General of French West African 1915 and of which Maurice Delafosse was a member. The International African Institute was established in 1926 in London, and former governor of Nigeria, Frederick Lugard was the first chairman (members include Samir Amin, Karin Barber, Mary Douglas, E.E. Evans- Pritchard, Jack Goody, Jane Guyer, Bronislaw Malinowski, etc. The journal of the institute, Africa published numerous prestigious works) (Pan, 2000). From the 1930s to 1960s, London School of Economics, Oxford University and Cambridge University emerged as new bases of African anthropology research. Funded by the Rockefeller Foundation and other donors, these institutions attracted some talented British anthropologists such as A.R. Radcliffe-Brown, E.E. Evans-Pritchard, Charles Gabriel Seligman, Meyer Fortes. French African studies were based at the University of Paris and School for Advanced Studies in the Social Sciences. Groundbreaking works in African studies were mostly published in this period, such as Meyer Fortes' The Dynamics of Clanship among the Tallensi, E.E. Evans Pritchard's The Nuer and Witchcraft, Oracles and Magic among the Azande, Jack Goody's Death, Property and the Ancestors. These anthropological ethnographies have had enormous impact on the ensuing studies of marriage and family, kinship and social structure.

Generally speaking, the early "non-Western" regional studies were the cornerstones for anthropology. As for regional studies, the detailed and abundant archives have been conducive to later interdisciplinary studies and follow-up research. Since the school emerged in the era of colonization, it received vehement criticism after the 1960s. The subsequent development of regional studies and the anthropological methodologies and ethnographic writing skills they applied have undergone significant changes, and the traditional "non-Western" regional studies are gone.

\section{Regional studies of United States' anthropology}

As stated in the beginning, regional studies as a discipline originated in the United States' after WWII. The United States' regional studies (or area studies) are more systematic and larger in scale compared to other Western countries. Before WWII, the United States was not engaged in any systematic regional studies, and studies of foreign countries in universities were limited to European history, literature and the study of religious canons. Until 1940, most doctoral candidates trained to study non-Western civilizations chose the ancient world as their research themes, while less than sixty chose contemporary studies of non-Western ethnic groups (Szanton $\&$ Geng, 2004). However, tasked with the mission of studying cultures of the Other, anthropological research preceded that of other social scientists in initiating regional studies and laid a solid foundation for the heyday of United States' regional studies later on. American anthropologists have an apparent awareness of the regional. In addition to their excellent ethnographical writing, they have also 
constructed related theories for regional studies. Anthropological regional studies in the United States focus not only on traditional "non-Western" regions but also on local "others," primarily Native Americans.

Since early twentieth century, American historical anthropologists, headed by Franz Boas, launched full-scale, intensive research on Native American peoples. These studies classified the Native American cultures of different regions. As shown in Alfred L. Kroeber's work Cultural and Natural Areas of North America, sources from hundreds of tribes were collected and marked with their features. Then, all these maps were put together into a cultural cartography of North America. Meanwhile, a large number of archives were collected and catalogued, and comprehensive volumes of ethnographies were compiled. Begun by Murdock at Yale University in 1949, the Human Relations Area Files, an extended archiving system, incorporated 330 different ethnic, cultural, religious, and national groups worldwide. It was coded in a way that researchers could quickly retrieve samples from archives. The documentation not only provided raw materials but a methodology for the later development of area studies in the US.

Besides these rich archives, United States' anthropologists theorized the relationship between cultures and regions, among which the culture area theory is the most typical and widely used one. This theory was formalized by Franz Boas in his classification of ethnographies, which was later elaborated on by Clark Wissler. The culture area theory focused on the origin, development, stabilization, and decline of a culture in a given region, and it is one of the most useful research tools on regional culture offered by American anthropologists. Wissler depicted culture as a complex of the traits manifested in a social group or a tribe (Wissler, 1923). Cultural areas can be identified according to the distribution of these traits. Specifically, Wissler classified native North American tribes into fifteen cultural areas and mapped out a series of maps with cultural phenomena marked on them. He also came up with the notion of Age and Area, related to the history of cultural dissemination, suggesting that cultural traits distributed in a larger territory belong to a more distant past than those confined within a smaller territory. Wissler's methods, which included both spatial and temporal factors, later became exemplary in regional studies, so did the ways he classified cultural traits and charted cultural areas.

After WWII, the United States expanded the scope of regional studies from Western European countries to the whole world and set up a large number of regional studies institutes in universities for various purposes. The funds came from the Ford, Fulbright and other major foundations. At this stage, American anthropologists worked to become specialists of different regions of the world as, for example, West Africanists or sinologists (Szanton \& Geng, 2004). Regional studies in the United States reached its peak in the 1960s and 1970s and it was sustained until the beginning of the twenty-first century. Contemporary American anthropologists and regional studies experts are still actively seeking new approaches for the discipline.

\section{The criticism and transformation of the regional studies of the "other"}

Since the 1960s, postmodernism swept across all the humanities in Western countries including anthropology, and regional studies of non-Western countries were affected. This crisis was two-fold. On the one hand, postcolonialism critique 
blamed anthropological study of non-Western areas for bearing a robust colonialist flavor as the authors of works on non-Western histories held overwhelmingly unequal power over local people and thus were party to so-called "cultural hegemony." (Adams, 2003) The ethnographic writing itself was challenged, and as anthropologists bogged down in the crisis of the discipline and the adjustment of disciplinary narratives, the once organized regional studies of non-Western areas gradually came to a halt. On the other hand, as far as politics and economy are concerned, many institutions initially set up for colonial purposes were dissolved, and regional studies of Africa, South Asia and South America lost institutional support and funding. Additionally, some colonies began to purposefully reject the entry of Western researchers. Anthropologists lost their field sites, and regional studies on non-Western countries became stagnant.

The rise of regional studies in the United States was partly due to the discipline being regarded as a political investment by the US after WWII (when the United States tried to learn about non-Western countries), and the later criticism against America's regional studies pointed at this intention, denouncing regional studies as merely a political movement. The charge was consistent with the criticisms leveled against regional studies conducted by other Western counties, for the latter had been equally hegemonic over "the Other." Since the advent of the twenty-first century, the United States adjusted its foreign policy, causing foundations to cut their budgets for research on international relations and regional studies, and regional studies declined for a period.

It is noted that anthropologists' reflections during the disciplinary crisis and the subsequently diversified ethnographic writing styles contributed to a revival of regional studies afterwards. As non-Western countries gained independence economically and politically, a large number of non-Western anthropologists began research in their native countries. These research works have often taken a post-colonial stance and offer a renovated perspective in interpreting regional cultures. In the meantime, Western anthropologists put more emphasis on the study of modern societies, and regional studies of the West emerged. The traditional research paradigm of the "Other" thus underwent a crucial transformation.

Contemporary anthropological regional studies that carry on the tradition of ethnography are exploring new topics from regional studies. Anthropologists who conduct regional studies not only intend to understand regional cultures but also how people, goods, and resources flow among regions. The new theme sheds light on the study of ethnic groups and their relationships, on the local market in the context of globalization, and on migrant studies and so forth, and gives rise to some new trends in anthropological regional studies. Although regional studies are no longer a tool to merely understand "Others" and cannot be labeled as "Western" or "non-Western," regional studies will continue to link people from different regions and to enhance cultural communication among them.

Beyond village: The regional studies for China's anthropology

China has a vast territory, rich geographical types and a great number of ethnic groups. Each humanities discipline in China has some regional study elements; in 
particular, the field of social history has detailed classification of China's regions and abundant research findings. When it comes to China's anthropology, however, the study of villages is a familiar approach, utilizing anthropological methods appropriate to simple, closed communities. This has led to the adverse situation that sees regional studies less mentioned and valued by China's anthropologists.

Anthropology was introduced to China in early twentieth century by western scholars and their Chinese students. Therefore, China's anthropological regional study was initiated with a significant perspective of viewing as an "outsider", even those native Chinese anthropologists who inherited the approaches and theories of traditional (western) regional study. However, the discourse power on China's anthropology was transfer from westerners to Chinese after 1950s, especially in Taiwan. The concept of regional study in Chinese context was slow drifting away from its original concept, it is still the macro perspective on a cultural region, yet its span was narrowed from international to domestic regions. China's regional study somehow resembling the regional study on native American, both conducted by disciplinary anthropologist on indigenous people, both ascending from tribe/village level to cultural sphere level, but the most important difference is the Chinese researchers are the native descendants while the Americans are not cultural coherent with their objects.

With a closer examination, however, China's anthropologists have not thoroughly dismissed the significance of regional studies. Regional studies remain the primary tool by which cases of villages are integrated to achieve a holistic knowledge of the region. Most of the early regional studies were promoted by overseas sinologists and scholars based in Taiwan. In the mid-twentieth century, Fei Hsiao-Tung advocated that Chinese anthropologists conduct regional studies consciously through comparison of village communities. From that point on, Chinese anthropologists subscribed to an ever more evident and holistic regional research approach. So far, China's anthropologists' work in regional studies, while inheriting the research tradition from their predecessors, has expanded research themes on urban studies, migration and ethnic groups, regional relationships, and so on.

\section{Beyond the village: Several paradigms of regional studies for China's anthropology}

In China's anthropological tradition, regional studies include the research of regional society on a larger geographical scale than villages. "Anthropological regional study involves a series of research frameworks developed by anthropologists not content, themselves, with village research mode." (Du, 2012) In the continuum from micro-community research to that of macro-regional research, China's anthropological research paradigms can be classified into three categories, namely George William Skinner's marketing system theory, Taiwan's worship circle theory, and the historical anthropology research on South China. The three paradigms of China's anthropological regional studies will be reviewed in the following. 
Anthropology was introduced to China in the 1920s and 30s, when anthropologists such as Alfred Radcliffe-Brown and Raymond Firth favored studying Chinese villages. They assumed that the study of many different micro village communities would lead to a holistic understanding of Chinese society ( $\mathrm{Du}, 2012)$. This perspective had a distinct overtone of British functionalism and was soon criticized by those academics who held that the functional analysis of a village was not suitably scalable to complex civilizations with a long history such as China. Research at village level could not be generalized from conclusions at a micro level. Later on, Skinner challenged the research paradigm of village studies in the 1940s by pointing out that the key to understanding the social structure of China was the necessity of understanding the exchanges within the market network of villages. He developed an alternative to China's regional study paradigm that became known as the marketing system theory. The marketing system theory divides China's society geographically, into nine macroregions, namely Northwest China, North China, Upper Yangtze, Middle Yangtze, Lower Yangtze, Southeast coast, Yungui, Manchuria, and Lingnan; while vertically dividing China's society into many strata and several historical periods in line with economic rises and falls. Additionally, he applied region theory and the principle of "central places" to investigate the internal composition and external relations among regions. Skinner's marketing system theory is a complete set of regional research methods that integrate micro-level community research into a genuine study of the macro. Scholarly criticisms of Skinner's theory follow two lines of thought. Firstly, Skinner seems to have moved to one extreme when he considered economic factors instead of institutional ones. Although his breakthrough lies in the abandonment of administrative divisions and circular dynastic theory, he neglected the "state" factor that had shaped the formation of regions. Furthermore, geographical boundaries changed continuously throughout history and were not as static as when the late imperial system consolidated. The connections between different areas were not always linked by trade and markets, nor were these regions independent as depicted in Skinner's theory (Chen, 2007).

Scholars in China's Taiwan province developed the notion of the "worship circle" which denotes the territorial ties of folk religion. The notion was introduced by Yuzuru Okada and was substantiated by Zhang Kwang-Chih who led the "interdisciplinary comprehensive research plan of the Zhuo River and Dadu stream basin" in the 1970s and reached its zenith in Lin Meirong's work in the 1980s. A worship circle is a territorial unit in which residents collectively worship their common deities. It involves a common faith, a common territory, a common worship activity and unified organization as well as a pooling of expenditures for the worshipping. The worship circle model reveals that the territorial society is grounded on the worshipping of local deities, thus providing an alternative model other than the regional market approach. Indeed, scholarly work on the worship circle often refers to Skinner's notion of the marketing system, for both the religious and marketing system are inherently related (Szanton, 2004).

South China studies, on the other hand, originated from the overseas-initiated China studies of the 1950s and 1960s, when overseas scholars based their research on "peripheral regions" such as New Territory of Hong Kong, Taiwan and some 
overseas Chinese communities (comprised of expatriates from Fujian and Guangdong provinces mainly), at a time when mainland China was closed to the outside world. From the 1970s and onwards, the scope of this research paradigm spread to cover Guangdong and Fujian and neighboring provinces and continued to grow thanks to inputs from both Chinese anthropologists and historians. The South China studies focused on the documentation and organization of local records and historical literature while applying effective anthropological methods and writing ethnographies. Through in-depth investigation of South China's local lineages, faith and social integration, South China studies gradually evolved into a regional study model aimed at shedding light on the formation of Chinese civilization as a whole. In the meantime, South China studies placed the region in a wider web that linked China and the outside world together, while focusing on the "localized society." In 1993, in his keynote speech at a "symposium on local literature and South China Studies," David Faure highlighted the fluid territories of South China and its shifting ethnic boundaries and elaborated on the notion of "South China." $\mathrm{He}$ stressed the cultural content rather than territorial implications in Down to Earth: The Territorial Bond in South China, co-edited with Helen Siu. He pointed out that "South China" is not a fixed territory. Instead, it is a historical construct that serves as a laboratory for the understanding of China's history as substantiated by regional studies (Cai \& Meibao, 2000).

\section{Fei Hsiao-Tung's interests in regional studies}

To understand China and develop China on the basis of authentic understanding remained two missions throughout Fei Hsiao-Tung's academic life, with regional studies being crucial to such an understanding. Professor Fei's later research works were by and large about regional development: the demarcation of China's regions, the growth of regional economies, achieving regional coordination, as well as reaching equilibrium between natural ecology and human ecology, all of which were among his primary academic interests.

Adhering to regional studies as one of his main research themes, Fei Hsiao-Tung dedicated his entire academic life to the work in that field that can be briefly summarized as relating to the spectrum from village studies to small township studies to regional studies. This is also the ladder he constructed in order to achieve an understanding of the entire cultural system of China. He began with a survey of a village community, and published Economy of Jiang Village (Jiangcun Jingji) in the 1930s, which later became part of the anthropological canon. The book's original title was Peasant Life in China. Following the functionalist approach which sees tribal society as an autonomous, functional whole, Fei depicted various layers of the institutions in the village and integrated them into a functional whole so as to construct the lives of Chinese peasants. However, the model soon received many criticisms so that Fei himself realized that "whether a single community can represent the country's situation or not, given that China is such a country with such vast expanse." (Fei, 1990) He then initiated another series of large-scale field work in Yunnan Province and published the volume Three Villages of Yunnan. The three villages in Yunnan were entirely different from the 
village of Kaixuangong (Jiang village). Fei remarked in the foreword that despite the vast expanse of China's territory, the understanding of China as a whole could be reached by setting forth different types of villages, investigating each type in detail, and making a synthesis of all the types (Fei, 1996). After the foundation of the PRC, Fei carried out many investigations in different sites within China with the mission to identify ethnic groups. The regional variations in development made an impression on him. From the 1980s and onward, as the processes by which villages turned into townships increased their pace, Fei began his research on small towns and cities on the foundation of his village studies, which in his own account was "somehow the extension and expansion of my earlier investigation of Kaixuangong village" and "the frontier work of village studies at a new height." The township studies he proposed could be furthered extensively and comprehensively by comparing the Jiangsu case (where Kaixuangong village is located) and other cases from other provinces, as well as by exploring the complicated urban-rural relationship starting from villages to small townships to mid-sized cities and finally big cities. Fei then elaborated on the notion of the economic development model, which entails a holistic exploration of the context and conditions of a specific region for the sake of development and how such a model stands out as compared with other regions. By so doing he entered the research domain in which economic and social developments from different areas were compared, these granting him with insights on regional studies. In the following two decades, Fei carried out a series of regional investigations covering nearly all economic and cultural regions throughout China. He kept summarizing his research findings, systematically proposing in-depth regional developmental blueprints for various regions to guide the regional developments in these regions. These blueprints include the establishment of regional economic coordination zones and economic circles and belts, such as the multi-ethnic economic development zone in the upper reaches of the Yellow River, the Yangtze delta economic development zone, and the pan-Pearl River delta economic zone and so on. These blueprints also encapsulate guidelines for the regional developments in Central, and West China and the Tibet-Yi corridor. The Pearl River delta mode, South Jiangsu mode and Wenzhou mode were among the most famous regional development models he proposed.

Fei's approach to regional studies differs from all abovementioned anthropological regional studies in that he was very pragmatic. He aimed to develop the regional economy on the basis of a correct understanding of regions through regional studies. Meanwhile, he was emphatic that the maintenance of natural ecology and human ecology are equally crucial in the process of regional development. Thus, we can conclude that his approach was comprehensive and systematic. Fei, in his own account, remarked that.

This research theme [regional studies] requires a combination of microscopic/ macroscopic approaches, theories and practices, as well as humanities and geography. Unlike small township studies, it is even comprehensive, at least in that it took me sixty years from microscopic village studies to the comparative study of townships to the regional studies that I proposed as a research theme. This theme does not only require us to see the economic development of the whole country as a 'chess game,' but also in the context of the overall trend of global economic 
development. The length and scope of the theme are far beyond my lifespan; I just propose the topic and look forward to my colleagues joining hands with a shared vision and dedication to explore the subject (Fei, 1999).

The contemporary Chinese anthropological research work with a clear regional studies orientation, such as the "Tibet-Yi corridor studies," "Pearl River Delta studies," and "Southwest ethnic group studies," are all implemented according to the blueprint laid out by Fei Hsiao-Tung. In the meantime, the scope and content of regional studies in anthropology have been expanding. The advent of globalization, as well as the changes in China's demography such as population growth and migration, however, bring new challenges to contemporary China's regional studies, as we shall discuss later.

\section{Regional studies by the anthropology department at sun Yat-Sen University}

The Department of Anthropology at Sun Yat-Sen University was restored in 1981. From then on it was dedicated to the combination of ethnographic and regional studies. The first regional study program initiated by its first dean, Dr. Liang Zhaotao, was the Hainan Island research plan that involved ethnology, linguistics, physical anthropology, and archeology in order to study the culture of the ethnic Li. Since the research plan involved various disciplines and perspectives and was regionally oriented, it marked the milestone of ethnohistory and minority anthropology in Hainan Island. This plan has generated many excellent ethnographies and theses and laid the cornerstone of a tradition of Hainan Island studies in the Department of Anthropology at Sun Yat-Sen University. The investigations of Hainan Island in the 1980s concentrated on ethnographic writings on local history, culture and the physical traits of the local Li ethnic group, while the large-scale survey was primarily on the measurement of the physical features of the local people. These research activities have attracted a number of scholars from the department including Zhang Shouqi, Huang Xinmei, Zhang Jianjun, and Xie Yeqi, etc., but have also caused repercussions within the local scholarship ${ }^{3}$. The studying of the physical traits and the culture of the Li ethnic group on Hainan Island continues to involve many more anthropologists, up to the advent of the new century, who are contributing to the establishment of a systematic regional research network. Until now, the Department of Anthropology at Sun Yat-Sen University retains its traditions of studying minorities on Hainan Island, leaving a traceable academic path and a treasure of masters and doctoral theses accumulated over the years. These ethnographies substantiate the regional studies of Hainan minorities. In a word, the Hainan Island research plan marked the opening of regional research in the Department of Anthropology at Sun Yat-Sen University. From then on, under Professor Liang Zhaotao, the department kicked off many more large-scale and systematic regional study programs and formed its unique research traditions.

\footnotetext{
${ }^{3}$ Author. These research works were published in the 1980s. For instance, the Acta Anthropologica Sinica published several articles on the physical anthropology of the Li ethnic group on Hainan Island. The study on the transformation of the Li ethnic group by Zhang Shouqi and Huang Xinmei was published in 1986.
} 
After her joining Sun Yat-Sen University in 1987, Professor Huang Shupin proposed three research directions for the department. While keeping theoretical research as an academic strength, she stressed that the department should study Guangdong Province and the Han ethnic group and that research programs should address practical issues. In line with these directions, Professor Huang initiated and supervised the research program on the cultural region of Lingnan (the region south of the five mountain ranges running through Guangdong, Guangxi, and Guizhou provinces), and dedicated herself to the study of the regional culture of the Han people. She researched the three branches of the Han, namely the Guangfu, Chaoshan, and the Hakka; the regional cultures of Guangdong and Hong Kong; the tenant system xizai; and Han communities in Taishan county, known as the "first hometown to Chinese overseas compatriots." Her research findings were compiled in Guangdong Ethnic Groups and Regional Cultural Studies and Report of Ethnic Groups and Regional Cultures of Guangdong and other publications. The regional studies of the Lingnan area undertaken in the Department of Anthropology at Sun Yat-Sen University fully embody anthropological scholarship with a history flavor, and the integration of historical literature, as well as the detailed on-site investigations, leaves us a relatively integral social and cultural landscape of the local society. Professor Huang's anthropological regional studies became comprehensive in the 1980s, allowing the department to engage in a systematic study regarding the regions inhabited by the Han ethnic group. Professor Huang's leadership of the department's was succeeded by Professor Zhou Daming, who carries forward the research on the ethnic groups of the Lingnan region into the new era. Following established academic traditions, the regional studies of the Lingnan area follow contemporary trends and have become a crucial element of the Sun Yat-Sen University's Department of Anthropology.

While both Liang Zhaotao and Huang Shupin held similar perspectives on regional studies, their emphases were different. Liang focused on minority ethnic groups, while Huang was concerned more about the Han ethnic group in the Lingnan area. Bearing the legacies of his predecessors, Zhou Daming carries the spirit of regional studies forward. While keeping an eye on the Lingnan area in the Pearl River basin and exploring its social change and issues related to ethnic groups, he spares attention to the minority ethnic groups in the region and their interactions with one another, their ecologies, and cultural changes in the contemporary era. He has worked as the primary investigator of two regional studies programs, namely that studying the "civilization in the Pearl River basin and interactions among ethnic groups," and one focusing on "the ethnic corridor of Nanling," both of which have involved many scholars as well as masters and PhD students from Sun Yat-Sen University. Many undergraduate students have also chosen their field sites in this region (From 2003 to 2011, the number of master and PhD theses of the Department of Anthropology at Sun Yat-Sen University amounted to twenty-three. From 1984 and onward, the department organized field work 16 times for its undergraduate students and published field investigations and reports. See Ma Guoqing, 2013). These academic endeavors contribute to the formation of a multi-disciplinary and sustainable scholarly tradition. The civilization of the Pearl River basin and ethnic studies remain the key research domains for the Department 
of Anthropology at Sun Yat-Sen University. Both involve the investigation of the social transformations taking place in the region over the past two decades, as well as the interactions and relationships among the many ethnic groups within the region. Furthermore, Zhou has set up the Center for Migration and Ethnic Studies and established a number of sites of field investigation. With the passage of time, the center has published a rich body of articles, theses and monographs, making cultural studies of the Pearl River region a phenomenal subfield. From 2012 and onwards, Prof Ma Guoqing's research of South China and pan-South China Sea regions has brought the regional studies of the anthropology department to a new height. The research program entails an ambition to study a larger territory from various angles, aiming at incorporating multiple disciplines including anthropology, archaeology, geography, and history so as to advance regional studies in this new territory.

\section{Conclusions: Challenges facing regional studies and some new trends}

We can conclude from the review of the abovementioned literature the differences between scholarly traditions from home and abroad. While Western regional studies aim to understand the Other, the ultimate aim of China's regional studies is to understand the Self, that is the whole of China through regional studies, regardless of the nationality of its precursors and advocators such as Skinner, Freedman, Fei Hsiao-Tung and scholars from the South China studies school. Overall, regional studies serve to bridge the understanding of particular cases and that of the whole region. This approach, however, faces many challenges in the contemporary world of globalization. Globalization in general has caused worldwide migration and cultural exchanges, the declining influence of nation-states, and the blurring of regional boundaries. It brings to the fore questions for anthropologists, such as to how to plan and position regional studies and how to carry forward regional studies through integrating multiple disciplines. As far as Chinese anthropologists are concerned, aside from meeting the challenges resulting from globalization, their tasks also involve the inheritance of the legacies of regional studies given by their forerunners. Regional studies in China are therefore undergoing an era of transformation.

Regional studies in an era of globalization

Globalization has become an irreversible trend that has swept all over the world since the new millennium. In contrast to the contemporary globalization, conventionally demarcated regions within regional studies seem to be associated with closed-ness and fixed boundaries. Some scholars tend to think that the notion of region per se is has been destabilized. One line of thought would have the notion of roots being replaced by routes in this ever-globalizing world. Given that population flows and exchanges take place incessantly, the once obvious distinction between space and place has been eroded (Ellis, 2004). In other words, will the foundation of regional studies destabilize when the cultural features of regions 
become less prominent and the demarcation of regional boundaries blur? This suspicion has a considerable impact on regional studies in the West, particularly in the United States. Being one of the leading countries engaged in regional studies, the US has been cutting related research budgets, with narratives of regional studies giving way to globalization. As a consequence, many of the research centers devoted to regional studies cannot sustain themselves.

In the authors' opinion, however, regional studies are as meaningful as they were in the past, and regional studies should carry on in the domain of anthropology. Indeed, in the context of globalization, the boundaries between regions are blurred and the synthesis of cultures is common, meaning that a given region can host multiple ethnic groups and various culture types. Insofar as that multiculturalism is inevitable within such a region, regional studies are indispensable. In addition, it is practical for the inhabitants in multicultural regions to understand the cultures of one another, to embrace positive cultural interactions, and to eliminate harmful cultural conflicts. Besides, since every single culture has evolved from specific geographical and historical conditions throughout time, it is hard for migrants to cut off their ties with home cultures. Therefore, in order to study migrants, ethnic groups, cultural interactions, as well as cultural change in the contemporary world, it is a must to trace the roots which are embedded in the soil of knowledge of regional studies.

The concepts of globalization and regions are not contradictory, though; globalization does not imply the disappearance of regional societies. According to Anthony Giddens, "globalization can thus be defined as the intensification of worldwide social relations which link distinct localities in such a way that local happenings are shaped by events occurring many miles away." (Giddens, 1990) Therefore, it is still necessary to study the regions comprised of different locales. Furthermore, owing to the close cultural links between regions, we must pay attention to the relationships and interactions among regions and make comparisons between them. By so doing, we will clearly see the formation of globalization and will be able to draw a timeline of the global cultural changes in the contemporary era.

The unique methods and research tools as well as its emphasis on local knowledge make anthropology suitable and applicable to regional studies. First of all, anthropological studies should follow academic tradition and study cultural change, migration, political and economic institutions and ethnic relations in a well-demarcated geographical region, while sparing attention to underdeveloped areas. These areas are often former colonial territories where a rich compilation of regional ethnographies can be found. In addition, the residual local identity and the cultural hegemony imposed upon these regions as well as the localized form of globalization are all topics worthy of study. Second, anthropology, as a discipline focusing on humankind and culture, should go beyond the limits of territory and take the mobile populations within regions as its research subjects. In other words, regional studies do not have to be geographically bounded; the focus is instead on the mobile population, that is, the migrants. Indeed, the study of the flow, cultural identity, and social stratification found on a global scale as it relates to the people from a specific region should be classified as regional studies, while the origin of 
migrants and their migration routes should become essential research themes of globalization research.

Finally, regional studies in an era of globalization have become increasingly complex and diverse. It poses both challenges and opportunities to anthropologists. How to meet such challenges and develop the discipline thus becomes a joint endeavor for all of our fellow colleagues.

Reflections on contemporary China's regional studies and new directions

Regional studies in Chinese context is different to its original western concept, therefore, when the discussion of globalization is overwhelming the international regional studies in western anthropology, Chinese "beyond village" regional studies may thrive in the increasingly frequent domestic communication. The declining of village due to fast industrialization in China, making the vessel of culture has been promoted from the village to the regional level. Both globalization and political economic reform have had significant impacts on regional studies in China. First, the loosening of the household registration system has allowed for a more frequent flow of the domestic population, which has reached an unprecedented $\operatorname{level}^{4}$. As a result of cross-regional migration, both the cultures of the native places and the destinations of migration have been transformed and it has become hard to identify certain regional cultural types. Secondly, the urbanization of China's villages is rapidly increasing and the urban-rural gap has been diminishing since the start of the twenty-first century. Meanwhile, the means by which village lineages, folk beliefs, and local societies are integrated have also changed, which has challenged the conventional methods of anthropological regional studies that often begin with village studies. The subsequent blurring of regional boundaries as well as the diversification and complexity of ethnic/cultural composition pose new challenges to China's contemporary regional studies.

There has been few renovated, comprehensive methodology for regional studies proposed by scholars after Fei Hsiao-Tung. In most cases, researchers follow either the path of South China studies or the regional studies offered by Fei. Scholars following the former approach have produced a rich literature in the field of historical anthropology, while the latter approach excels in studying ethnic groups in minority regions (such as the ethnic studies of the "Tibet-Yi corridor") and proposing regional economic models (such as that of the urbanization of the Pearl River Delta). Both approaches have generated a number of excellent ethnographies and monographs. In addition to inheriting legacies from previous studies, recent scholarship is inspired by the fact that contemporary changes have caused transformations among the research subjects in any given region. Many research themes on migrants, ethnic groups and their relationships and cultural transformation have emerged in urban studies. All of these changes will effectively carry forward regional studies. It is noted that Chinese anthropologists in general are short of awareness of regional studies. This paradigm

\footnotetext{
${ }^{4}$ China's domestic migrant population reached 236 million by 2012. See the 2013 report on the development of mobile populations on the webpage of the PRC's state council, http://www.scio.gov.cn/ zhzc/8/4/Document/1345763/1345763.htm.
} 
was supposed to be an effective means to the compilation of individual cases so as to transcend village studies and reach an understanding of Chinese society through comparison. However, rarely do any anthropologists consciously examine different themes and various cases in a given region, and the regional studies within anthropology are far less than systematic.

The authors therefore propose that firstly, efforts should be made with regard to the integration of many anthropological research themes within a given region. Additionally, the establishment of regional studies associations and conferences are needed. Secondly, it is necessary to refer to disciplines with concrete regional research frameworks, such as history, geography, politics, and economics, and implement cross-disciplinary research programs in order to enrich the knowledge of a given region. Finally, regional studies in contemporary China should break the limits of geographical boundaries and engage new regional studies themes such as the roots and routes of migrants that are crucial to the frequently flows of populations. To summarize, the awareness of regional studies in the discipline of anthropology should be reawakened and enhanced. We should grasp opportunities and readjust our directions, for regional studies is, and will continue to serve as, a vital approach to the understanding of various regional cultures through comparison and add to the knowledge of the whole of Chinese society.

Acknowledgements Not applicable.

\section{Funding}

This article is a stage research result of "migration and urbanization", a key base project for ministry of education.

\section{Availability of data and materials}

Not applicable.

\section{Authors' contributions}

Original Chinese authors: ZD, ZX. English translators: CY (corresponding author), CL. All authors read and approved the final manuscript.

\section{Ethics approval and consent to participate}

Not applicable.

\section{Consent for publication}

The authors approved the translation and publication. 


\section{Competing interests}

The authors declare that they have no competing interests.

\section{Publisher's Note}

Springer Nature remains neutral with regard to jurisdictional claims in published maps and institutional affiliations.

\section{References}

Adams, W.M. 2003. In Decolonizing Nature: Strategies for Conservation in a post-Colonial Era, ed. Mulligan Martin. London: Earthscan.

Du, Jing. 2012. Beyond the Village: A Review on the Research about the Han People Area-society. EthnoNational Studies 1.

Ellis, RJ. 2004. "Decentering area studies," Understanding the World: Developing interdisciplinary area studies to meet the needs of the 21st century, Woburn House, London, 24 March 2004.

Giddens, Anthony. 1990. The Consequences of Modernity, 64. Cambridge: Polity Press.

Fei, Hsiao-Tung. 1990. "Humanities in China." in Dushu. Vol. 10.

Fei, Hsiao-Tung. 1996. Self-Account of My Academic Life and Some Reflections, 36. Sanlian Publishing House.

Fei, Hsiao-Tung. 1999. Collected works of Fei Hsiao-Tung. Vol. 14, 221. Qunyan Press.

Zhuang, Kongshao, Introduction to Anthropology, Taiyuan: Shanxi Educational Press, 2003, pp.12-13.

Pan, Huaqiong. 2000. African Anthropology Studies: Hope and Bump Co-exist. West Asia and Africa 3.

Chen, Qian, "Mei Guo Han Xue Jie Qu Yu Yan Jiu Shu Ping (Review on American Sinology Studies," Theory Horizon, vol.4, 2007.

Szanton, David L. 2004. "The Origin, Nature, and Challenges of Area Studies in the United States," in The Politics of Knowledge: Area Studies and the Disciplines edited by David L. Szanton. University of California Press. p. 1-33.

Szanton, David L., Geng, Xiang, ed., trans., "The Origin, Nature, and Challenges of Area Studies in the United States, Social Sciences Abroad," vol.1, 2004.

Wang, Mingming. 2011. Social Anthropology, 89. Taipei: Wunan Press.

Wissler, Clark. 1923. Man and Culture, 52. London: George G. Harrap.

Xin, Li. 2010. Social and Cultural Interaction on the Background of Globalization. Ethnography on the Southwest Frontier 1.

Cai, Zhixiang and Cheng Meibao. 2000. "South China Studies by Overseas Scholar," in Guang Ming Daily, 22 December 2000.

Zhou, Hong. 2012. Zhuang Kong-Shao's Methodological Inquiry of Research in Anthropology and Ethnology and its Meanings: Theories and Practices of the Chinese Epistemological Tradition and Regional Cultural Concepts. Minzu Tribune 3. 